\title{
Restoration of Five Digit Hand in Type III B \& C Thumb Hypoplasia-A Game Changer in Surgical Management
}

\author{
$\begin{array}{lll}\text { G. Balakrishnan } & \text { S. Vijayaragavan } & \text { B. Somesh }\end{array}$ \\ ${ }^{1}$ Department of Plastic, Hand \& Microsurgery, Right Hospitals, \\ Kilpauk, Chennai, Tamil Nadu, India \\ 2The Tamil Nadu Dr. MGR Medical University, Chennai, Tamil Nadu, \\ India
}

\begin{abstract}
Address for correspondence G. Balakrishnan, MCh, FRCS(England), DSc, Department of Plastic, Hand \& Microsurgery, Right Hospitals, Kilpauk, Chennai 600010, Tamil Nadu, India (e-mail: gbrighthospitals@gmail.com).
\end{abstract}

Indian J Plast Surg:2020;53:349-356

\begin{abstract}
Keywords

- congenital hand difference

- thumb hypoplasia

- Type III B \& C

- toe phalangeal transfer

- Huber's opponensplasty

Background Hypoplasia of thumb is the second common congenital difference of the thumb, next only to duplication. It may occur as an isolated hand difference or as a part of radial longitudinal deficiency. In approximately $60 \%$ of these children, the radius shows hypoplasia. The incidence of thumb hypoplasia is one in 100,000 live births. In $50 \%$ of these children, the other hand will also have similar deficiency, although variable in severity. Hypoplasia of thumb has been classified into five major categories, according to the increasing severity of hypoplasia. Type III hypoplasia of thumb is characterized by skeletal hypoplasia involving the first metacarpal and carpometacarpal joint, absent intrinsic muscles and rudimentary extrinsic muscles. It was further subclassified into types A, B \& C. Type III B, described by Manske and McCarroll, involves extensive deficiency of extrinsic and intrinsic musculature with aplasia of the metacarpal base. Type III C, described by Buck-Gramcko, has hypoplastic metacarpal head. Methods It is widely believed that reconstruction of Type III B \& C hypoplastic thumb will not be functionally useful, and they are often included in the indications for pollicization in thumb hypoplasia. In India, we frequently come across parents, who are not willing to remove the hypoplastic digit. This forced us to find out a way to reconstruct the hypoplastic thumb into a functionally useful digit. We describe our surgical technique of reconstruction of hypoplastic thumbs and our experience in utilization of the technique in five children with Type III B \& C hypoplasia of thumb. Carpometacarpal joint of thumb was reconstructed and stabilized with a toe phalangeal transfer in the first stage and an opponensplasty was done in the second stage to improve movement. Results In all the five operated children, our surgical technique yielded a stable thumb which was functional. The donor site morbidity was acceptable. The parents were satisfied with the appearance and functional improvement.

Conclusion Surgical reconstruction of hypoplastic thumbs of Type III B \& C is possible, and conversion of these poorly developed remnants into a useful digit by our surgical technique is a gamechanger in the management of thumb hypoplasia.
\end{abstract}

\section{Introduction}

Thumb hypoplasia involves deficiency in development of skeleton and soft tissues of the first ray. The common clinical presentation include diminished size of the thumb, adduction

published online

November 25, 2020
DOI https://doi.org/

$10.1055 / \mathrm{s}-0040-1718858$

ISSN 0970-0358. of first metacarpal, instability of metacarpophalangeal joint, deficiency of thenar muscles, dysplasia of the extrinsic flexor and extensor tendons, and hypoplastic or absent base of first metacarpal with carpometacarpal joint instability ${ }^{1}$

\section{(c) 2020. Association of Plastic Surgeons of India.}

This is an open access article published by Thieme under the terms of the Creative Commons Attribution-NonDerivative-NonCommercial-License, permitting copying and reproduction so long as the original work is given appropriate credit. Contents may not be used for commercial purposes, or adapted, remixed, transformed or built upon. (https://creativecommons.org/licenses/by-nc-nd/4.0/) Thieme Medical and Scientific Publishers Pvt. Ltd., A-12, 2nd Floor, Sector 2, Noida-201301 UP, India 
Thumb hypoplasia can occur either as an independent entity or as a component of longitudinal deficiency of the preaxial ray. Hypoplastic thumb can also be associated with duplication, symbrachydactyly, constriction ring syndrome or cleft hand.

\section{Classification}

Thumb hypoplasia was originally classified by Muller in 1937 into four categories. ${ }^{2}$ It was further expanded into five categories by Blauth in 1967. ${ }^{3}$ Blauth's classification is based on the increasing severity of the development of both skeleton and soft-tissue components. In 1992, Manske and McCarroll modified the Blauth classification by subdividing Type III into two categories. ${ }^{4}$ Type III A has an intact carpometacarpal joint, whereas Type III B has basal metacarpal aplasia and hence absent carpometacarpal joint. Later, BuckGramcko added another subcategory, Type III C with remnant of hypoplastic metacarpal head ${ }^{5}$ ( Table $\mathbf{1}$ ).

\section{Aim of Reconstruction}

The most important functional components of hand such as pinch, grasp and fine motor activities depend upon the stability and mobility of thumb. Reconstruction of thumb at an earlier age prevents the child from developing scissoring grip between index and middle fingers as a substitute for key pinch. The most vital decision to be made in thumb reconstruction in a congenital hand difference is either to reconstruct the existing hypoplastic digit or to use the index finger for pollicization. In India and most Asian countries, parents prefer to retain and reconstruct the hypoplastic digit rather than go in for pollicization. Five-fingered hand is always preferable in our society.

The reconstructed digit should have the stability and mobility to be functionally useful. As far as thumb is concerned, we always prefer to have a mobile carpometacarpal joint and a stable metacarpophalangeal joint and interphalangeal joint. Hypoplasia of thumb Types I, II \& III A have intact carpometacarpal joint and hence are always reconstructed. Type IV \& V often require pollicization because of

Table 1 Modified Blauth Classification of Hypoplasia of thumb

\begin{tabular}{|l|l|}
\hline Type & Findings \\
\hline I & Minor generalized Hypoplasia \\
\hline II & $\begin{array}{l}\text { Absence of Intrinsic thenar muscles } \\
\text { First web space narrowing } \\
\text { Ulnar collateral ligament insufficiency }\end{array}$ \\
\hline III & $\begin{array}{l}\text { Similar findings as Type II plus: } \\
\text { Extrinsic muscle and tendon abnormalities } \\
\text { Skeletal Deficiency } \\
\text { A: Stable carpometacarpal joint } \\
\text { B: Unstable carpometacarpal joint-(Manske) } \\
\text { C: Remnant head of metacarpal only-(Buck-Gramcko) }\end{array}$ \\
\hline IV & Pouce flottant or floating thumb \\
\hline V & Aplasia \\
\hline
\end{tabular}

the severity of hypoplasia. Type III B \& C are also often considered as an indication for pollicization by most of the hand surgeons across the globe. The aim of our reconstruction is to provide a stable and mobile carpometacarpal joint, so that the hypoplastic digit becomes functionally useful.

\section{Selection Criteria}

Children presenting with hypoplasia Type III B \& C only were selected. Only children with isolated thumb hypoplasia are selected. There was no associated radial longitudinal deficiency. Forearm bones were normal in all children. The distal segment of thumb should be of good shape with intact metacarpophalangeal joint and interphalangeal joint. The hypoplastic thumb should be placed proximally. The pedicle should be sufficiently wide to accommodate the harvested phalanx (-Fig. 1). The digits of donor foot should be normal, so that the proximal phalanx can be harvested.

Typical clinical presentation of these children may include blunt ending radius, hypoplastic or absent radial styloid process, small trapezium, absent scaphoid, and tapered first metacarpal bone with absent carpometacarpal joint (-Fig. 1).

\section{Surgical Technique}

The reconstruction was done in two stages. In the first stage, free phalangeal transfer was performed to provide stability and carpometacarpal joint reconstruction. The first stage was performed before the age of 18 months. By an incision along the radial border of wrist, a soft-tissue pocket was created between the proximal end of the existing first metacarpal and carpal bones. Usually a remnant of the abductor pollicis longus (APL) tendon will be present ( - Fig. 1). The tendon was dissected out and carefully preserved.

One or two phalanges can be harvested from the foot, depending upon the requirement of length needed for reconstruction. Proximal phalanges of the 3rd and 4th toes are utilized. The selection of the toe depends upon the space available between the bony segments and the size of the defect. We never harvest the phalanx from second toe. The second toe is preserved intact. In case, the child is not happy with the reconstructed thumb in the future, and demands for a microvascular reconstruction, the second toe will be available for toe transfer.

By a dorsal midline longitudinal incision over the proximal phalanx, extensor tendons retracted and the phalangeal bone exposed and dissected. Extraperiosteal harvest of the toe phalanx is performed. Adequate care must be taken not to injure the flexor tendons, especially over the joints. After harvesting the phalanx, the extensor tendon is sutured to the flexor tenon with a continuous stitch. This maneuver avoids shortening of the donor toe.

Harvested phalanx is placed in the pocket created in the wrist and held in place with a straight $\mathrm{K}$ wire. In case of double phalangeal harvest, the cartilaginous portions between both the phalanges were removed before inserting the $\mathrm{K}$ wire 

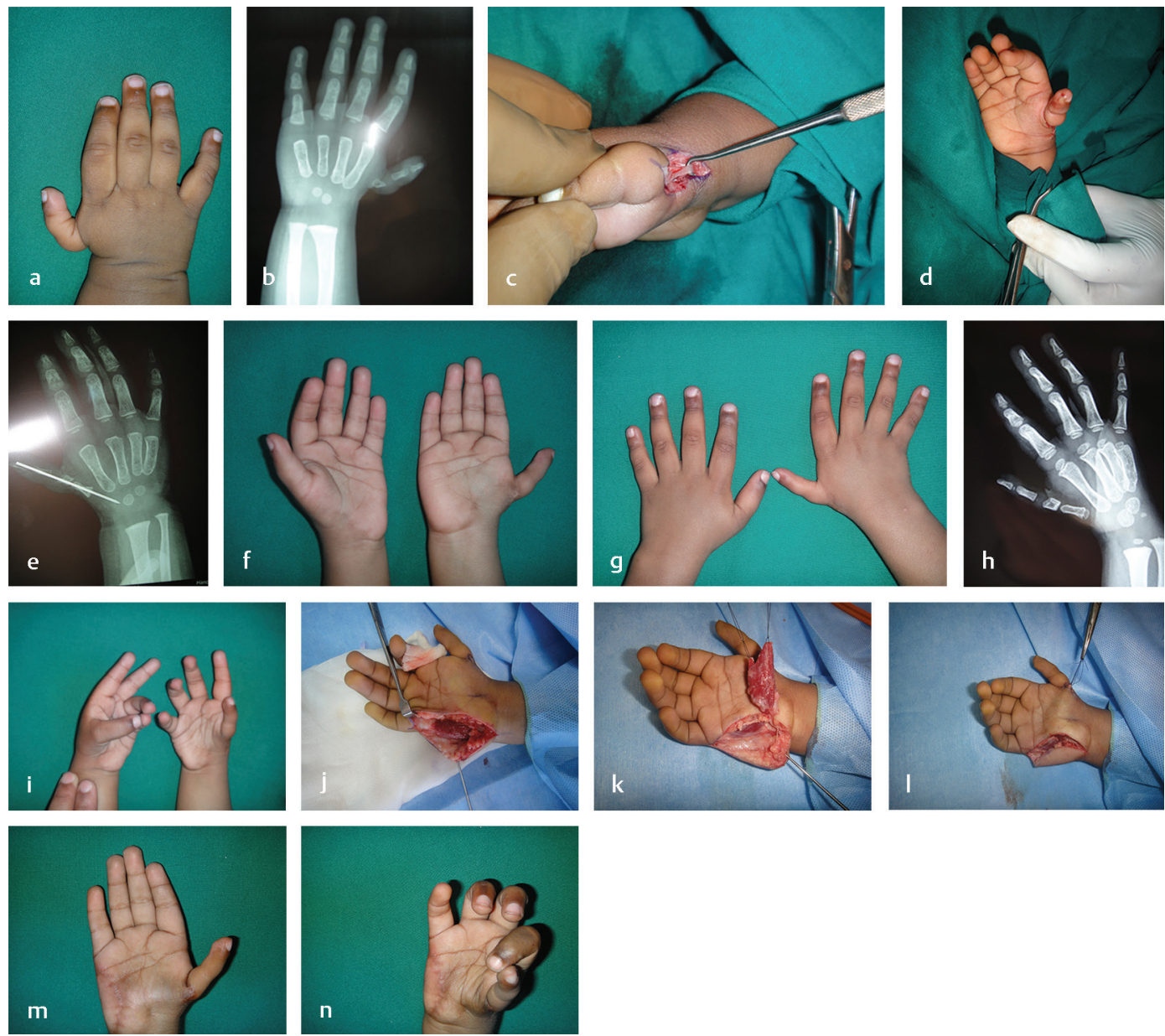

Fig. 1 Preoperative photograph of a child with Type III B thumb hypoplasia. (b) X-ray shows tapered first metacarpal bone with unstable carpometacarpal (CMC) joint. (c) Free phalangeal transfer-first stage of surgery. The remnant tendon abductor pollicis longus (APL) is hooked and retracted. (d \& e)-after free phalangeal transfer. (f \& g) Physical appearance of the thumb after free phalangeal transfer. (h) 1-year postoperative X-ray showing stable carpometacarpal (CMC) joint. There was no bone absorption. (i) Functional status of the thumb-not able to oppose. (j) Huber's opponensplasty-second stage of surgery-exposure of abductor digiti minimi (ADM). (k) Abductor digiti minimi (ADM) muscle harvest-two insertions one at base of proximal phalanx and another at the extensor expansion disengaged. (I) Abductor digiti minimi (ADM) tunneled subcutaneously and transferred. ( $\mathbf{m} \boldsymbol{\&} \mathbf{n}$ ) Postoperative function of reconstructed thumb showing good opposition.

to aid bony fusion between both phalanges (-Figs. 1). The APL tendon is reattached to the base of the harvested phalanx with a periosteal stitch. This provides stability of the carpometacarpal joint and also acts as an abductor of the thumb. The $\mathrm{K}$ wire is retained for a period of 8 weeks. Periodical assessment done at 3 months interval to assess stability of carpometacarpal joint of the reconstructed thumb clinically and radiologically ( - Figs. 1).

The second stage of surgery is planned after a period of 6 months. Abductor digiti minimi was used to provide opposition (Huber's opponensplasty). By a curved incision along the hypothenar eminence ( $\boldsymbol{- F i g .} \mathbf{1}$ ), abductor digiti minimi muscle was dissected out, divided at the insertion as two slips (one slip inserting into base of proximal phalanx and the second slip inserting into extensor expansion) ( - Fig. 1), islanded on the neurovascular pedicle, and brought subcutaneously to the metacarpophalangeal joint of thumb ( - Fig. 1 ). One slip of the distal tendon was sutured to the base of the proximal phalanx with a periosteal stitch and another slip to the MP joint capsule (-Figs. 1). Immobilization was performed for a period of 4 weeks. The child was encouraged to do physiotherapy after 1 month.

\section{Materials \& Methods}

Five children with Type III B \& C thumb hypoplasia underwent thumb reconstruction in our hospital between 2011 to 2019 (-Figs. 2). Three of them had Type III B and two of them had Type III C. Toe phalangeal transfer was performed before 18 months of age ( - Table 2 ) in four of three children ( - Figs. 3). One child underwent double phalangeal surgery at 10 years of age. Three children required single phalangeal transfer and two children required double phalangeal transfer. Proximal phalanx of fourth toe was the commonly used bone. When two phalanges are required, proximal phalanx of third and fourth toes are used (-Figs. 4 ).

The second stage of surgery was performed in three of these children. Two of them were happy with the movements available with the transfer of the remnant APL tendon and 

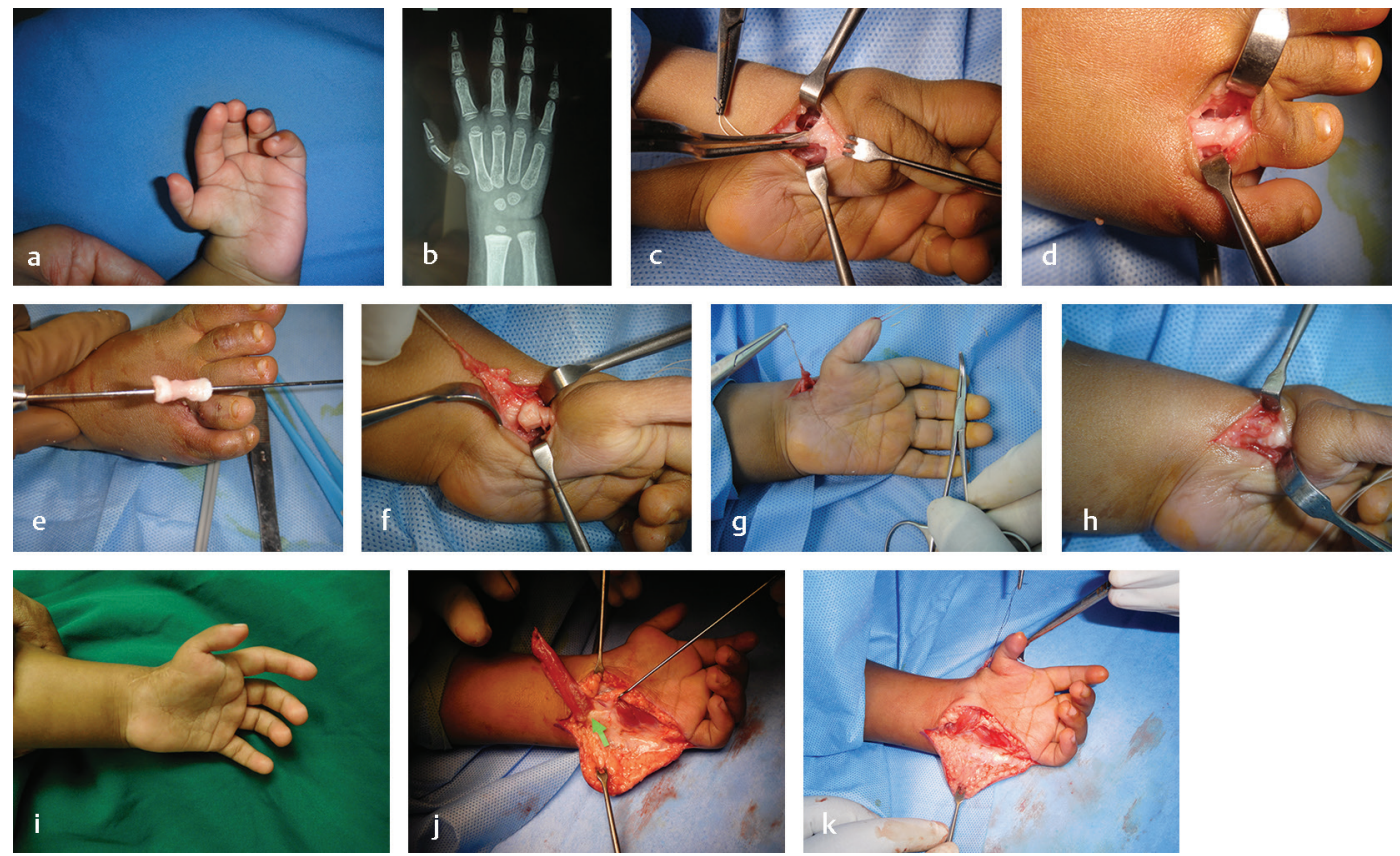

Fig. 2 b) Preoperative photo and X-ray of a child with Type III B hypoplasia-left thumb. (c) Free phalangeal transfer-pocket creation to accommodate the toe phalanx. (d) Toe phalanx harvested. (e) K wire passed through the toe phalanx. (f) Toe phalanx inserted into the pocket. (g \& h) Attachment of remnant abductor pollicis longus (APL) tendon to base of the transferred phalanx. (i) Postop appearance after first stage. ( $\mathbf{j}$ \& k) Huber's opponensplasty.

Table 2 Our list of patients and procedures underwent

\begin{tabular}{|l|l|l|l|}
\hline Patient & $\begin{array}{l}\text { Type of } \\
\text { hypoplasia }\end{array}$ & First procedure & Second procedure \\
\hline A & III B & $\begin{array}{l}\text { Free toe phalangeal transfer } \\
\text { done at 7 months }\end{array}$ & $\begin{array}{l}\text { Huber's opponensplasty } \\
\text { done at 3 years }\end{array}$ \\
\hline B & III B & $\begin{array}{l}\text { Free toe phalangeal transfer } \\
\text { done at 18 months }\end{array}$ & $\begin{array}{l}\text { Huber's opponensplasty } \\
\text { done at 2 years }\end{array}$ \\
\hline C & III B & $\begin{array}{l}\text { Free Toe phalangeal transfer } \\
\text { done at 10 months }\end{array}$ & $\begin{array}{l}\text { Huber's opponensplasty } \\
\text { done at 2 years }\end{array}$ \\
\hline D & III C & $\begin{array}{l}\text { Double toe phalangeal transfer } \\
\text { done at 10 years }\end{array}$ & - \\
\hline E & III C & $\begin{array}{l}\text { Double toe phalangeal transfer } \\
\text { done at 15 months }\end{array}$ & - \\
\hline
\end{tabular}

they refused to undergo second surgery. The children were able to hold objects. They were able to hold a pen and write (Video 1).

\section{Video 1}

Postoperative function after double phalangeal transfer. The child is able to hold objects using the reconstructed right thumb. Child is also able to hold a pen and write. Parents not willing for second procedure. Online content including video sequences viewable at:https://www.thieme-connect. com/products/ejournals/html/10.1055/s-0040-1718858.

\section{Results}

There were no complications noted with this procedure. All the transferred phalanges survived. There was no bone absorption. Even in the child who underwent double phalangeal transfer at 10 years of age, the phalanges underwent no absorption. They survived fully and the fused bones formed a stable thumb. The carpometacarpal joint was found stable in the follow-up X-rays. The stability is assessed by the position of base of the reconstructed metacarpal. It remained in alignment with the carpal bones. There was no slipping or sliding.

Clinically, carpometacarpal joint stability can be assessed by observing lateral displacement of lifting of base of first metacarpal when the child performs pulp to pulp pinch. 

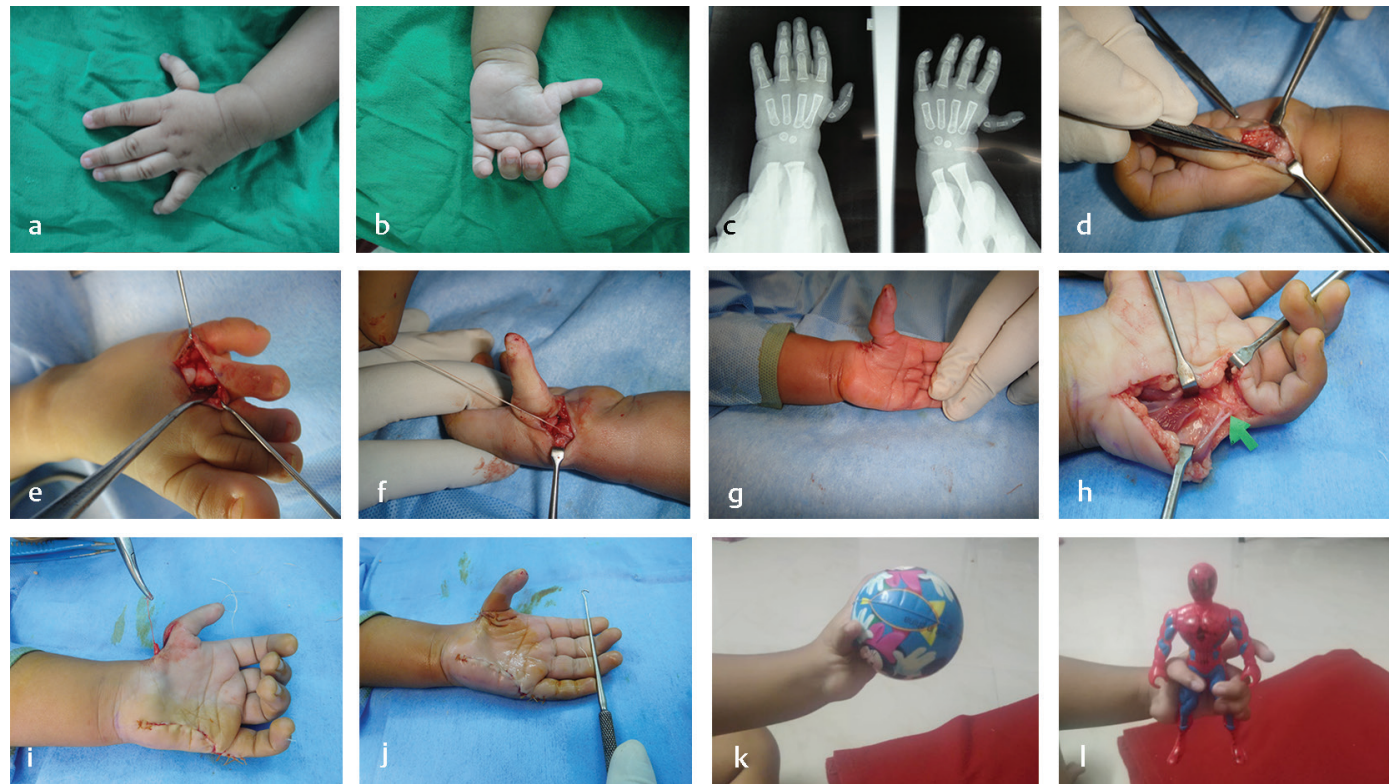

Fig. 3 Preoperative appearance of hypoplastic thumb Type III B. (c) Preoperative X-ray. (d, e, f) Toe phalangeal transfer. (g) Appearance after first stage of surgery. (h, $\mathbf{i}, \mathbf{j})$ Steps of second stage of surgery-Huber's opponensplasty. (k, I) Child able to hold objects after reconstruction.


Fig. 4 , b) Preoperative appearance of hypoplastic thumb Type III C-10-year-old child. (c) Preoperative X-ray. (d, e, f)-double phalangeal transfer. $(\mathbf{g}, \mathbf{h})$-postop appearance. (i) 9 years postoperative X-ray showing full survival of the phalanges without any absorption. 
None of these children developed the deformity, and the carpometacarpal joints were stable.

All the children were able to incorporate the reconstructed thumb in day-to-day activities. There did not develop the scissoring grip between index and middle fingers. This postoperative video shows the child using the reconstructed thumb to grasp glass marbles (Video 2).

\section{Video 2}

Postop functional status of reconstructed left thumb. Child is able to hold glass marbles using the reconstructed thumb. Online content including video sequences viewable at:https://www.thieme-connect .com/products/ ejournals/html/10.1055/s-0040-1718858.

Mean follow-up period was 2 years. Longest follow-up period was 9 years after surgery. Follow-up X-rays were taken at an interval of 6 months. These X-rays showed no body absorption of these phalanges ( - Fig. 4).

Opposition movement obtained after surgery was measured by the Karpandji score. Of the three patients who underwent both stages of surgery, two children achieved a Karpandji score of 6 and the third child achieved a Karpandji score of 7 at the end of 1 year after surgery. Both the children, who were not willing to undergo the second stage of surgery, attained a Karpandji score 4 of opposition. This postoperative video shows the ability of the reconstructed thumb to oppose with the tip of little finger (Video 3 ).

\section{Video 3}

Postoperative functional status of another child who underwent reconstruction of left thumb. The child is able to oppose the thumb to the tip of the little finger. Online content including video sequences viewable at:https://www. thieme-connect.com/products/ejournals/html/10.1055/ S-0040-1718858.

A North Coast Pinch Gauge is used to measure the strength of the reconstructed thumb (-Figs. 5 ). Assessment of strength was done 1 year after the completion of second stage of surgery. For the two children, who were not willing for second stage, assessment was done after 1 year of first surgery.

The pulp to pulp and lateral grip strengths between thumb and index fingers were measured in these children and compared with that of the contralateral normal thumb. The average pulp to pulp grip strength achieved with the procedure was $42 \%$ of the normal thumb. The average lateral grip strength was $28 \%$ of the normal thumb.

The donor site scar was acceptable. The donor toe was shortened due to loss of a phalanx. However, there was no angulation, deformity or instability (-Fig. 6).

Satisfaction of the parents was assessed by a questionnaire ( - Table 3 ). They were asked to fill up the questionnaire
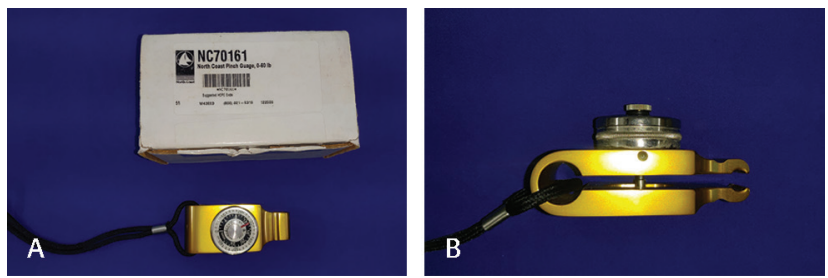

Fig. 5 North Coast Pinch Gauge, which was used to assess the pulp to pulp and lateral grip strengths after thumb reconstruction.

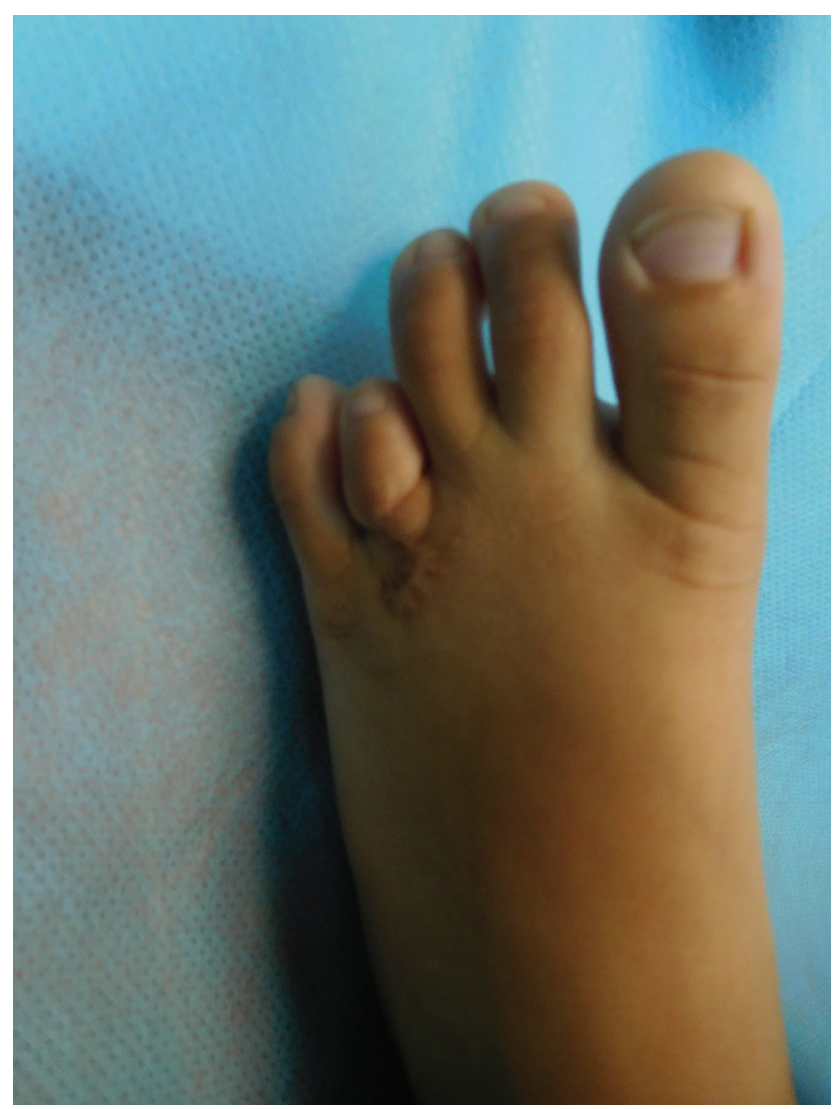

Fig. 6 3-year follow-up picture of donor foot after phalangeal harvest. The scar was acceptable. The donor toe (fourth toe) was shortened. There was no angulation or deformity.

3 years after completion of surgeries. Parents of all five children were satisfied with the appearance and function of the reconstructed thumb.

\section{Discussion}

The major dilemma in surgical reconstruction of Type III B \& $C$ hypoplastic thumb is whether to retain the hypoplastic thumb and restore a five-digit hand or proceed with pollicization of index finger, which would result in a four digit hand. The decision-making is a complicated process because of the severity of hypoplasia, parents request and social obligations.

Most of the hand surgeons across the globe prefer pollicization of index to provide a satisfactorily functioning thumb. ${ }^{6-8}$ But in most of the Asian countries including India, 
Table 3 Questionnaire for assessment of parents' satisfaction

\begin{tabular}{|l|l|l|l|l|l|}
\hline & $\begin{array}{l}5 \\
\text { (Very much } \\
\text { satisfied) }\end{array}$ & $\begin{array}{l}4 \\
\text { (Satisfied) }\end{array}$ & $\begin{array}{l}3 \\
\text { (Somewhat } \\
\text { Better) }\end{array}$ & $\begin{array}{l}\mathbf{2} \\
\text { (Dissatisfied) }\end{array}$ & $\begin{array}{l}\text { (Very much } \\
\text { Dissatisfied) }\end{array}$ \\
\hline Appearance of thumb & & & & & \\
\hline $\begin{array}{l}\text { Inclusion of thumb in } \\
\text { routine activities of hand }\end{array}$ & & & & & \\
\hline Holding objects & & & & & \\
\hline Writing & & & & & \\
\hline Picking up small objects & & & & & \\
\hline Enough force & & & & & YES \\
\hline Preferential hand usage & & & & & \\
\hline Donor foot Appearance & & & & \\
\hline $\begin{array}{l}\text { Overall Functional } \\
\text { surgery }\end{array}$ & & & & \\
\hline $\begin{array}{l}\text { Have you ever regretted } \\
\text { your decision to choose } \\
\text { this procedure }\end{array}$ & NO & & & \\
\hline
\end{tabular}

Assessment of results.

$>40$-Satisfied with the surgery.

30-40-Not up to the expectation.

$<30-$ Not satisfactory.

the parents want the child to have a five-digit hand, even though the reconstructed thumb is not fully functional.

Chow et al reconstructed the hypoplastic thumb with hemilongitudinal metatarsal transfer. Part of the fourth metatarsal bone was used as a nonvascularized bone graft in Grade III B \& Grade IV thumb hypoplasia. ${ }^{9}$ Vascularized second metatarsal bone transfer for reconstruction of Grade III B thumb hypoplasia was described by Schneider et al. ${ }^{10}$

Reconstruction of Type III B hypoplastic thumb by free vascularized metatarsophalangeal joint transfer to reconstruct carpometacarpal joint was described by Foucher et al. ${ }^{11} \mathrm{He}$ analyzed five patients who underwent this procedure and concluded the procedure should be reserved for children whose parents are not willing for pollicization.

The second toe transfer with metatarsal bone for thumb hypoplasia Type III B, IV \& V was described by Tu et al. ${ }^{12}$ They described a technique of total second toe transfer with carpometacarpal joint arthrodesis and tendon rebalancing of the metacarpophalangeal joint.

For hypoplastic thumbs of grade III B V, pollicization remained the gold standard reconstructive surgery of choice. It has the advantages of single-staged procedure, and shorter operative time restores good functional range of motion and achieves maximum grip and grasp strengths; however, it also has got its demerits. When compared with to the normal thumb, the pollicized index finger attains only $21 \%$ of the grip strength and 22 to $26 \%$ of tip pinch and tripod pinch. Mobility of reconstructed thumb is also $50 \%$ of the normal thumb. ${ }^{13}$ Other strategies of thumb reconstruction in Type III B hypoplasia are not fully studied and remains an area for exploration of possibilities. There are not many papers in the literature also.
A comparative study was performed to measure the outcomes between pollicization and microsurgical second toe-metatarsal reconstruction was performed by Tan et al in 2013. They concluded that early motor and sensory recovery was achieved in children who underwent pollicization. The functional result and range of motion were better in pollicization group than the children who underwent microsurgical reconstruction. However, the parents of children who underwent microsurgical reconstruction had higher rate of satisfaction. ${ }^{14}$

The traditional views regarding thumb reconstruction such as providing a structurally stable, functionally mobile, aesthetically pleasing radial post still holds good. But, in the modern world, with decreasing need of manual labor and lesser usage of power tools and heavier instruments, providing a less powerful but aesthetically more pleasing thumb is not at all a bad reconstructive option. ${ }^{15}$

With the increasing usage of touch screens and automation mechanisms in various tools and gadgets in day-to-day activities of modern life, the need for reconstruction of a powerful thumb to restore stronger grip and grasp is becoming lesser. Parents prefer their children to have five fingered hands even though the reconstructed thumb is less powerful than pollicized index finger.

The cultural and religious values persisting among the society to restore all five digits of hand often forces the parents the request for reconstruction whenever possible. As far as Stage III B \& C thumbs are concerned, providing a stable and mobile carpometacarpal joint is vital for the reconstructed thumb to have optimum function. Our surgical procedure satisfies this object and hence provides maximum satisfaction for the parents. 


\section{Conclusion}

Our reconstructive surgical procedure restores a stable and mobile carpometacarpal joint and henceforth, a useful thumb. It's a simple and reliable procedure with shorter operating time than a microvascular reconstructive surgery. The success behind the reconstruction is to reconstruct a stable carpometacarpal joint and provide mobility in the second stage. The two-staged reconstructive surgery restores a functionally useful aesthetically pleasing thumb, and parents were satisfied with the usage of reconstructed digit. When properly executed at appropriate age group, this provides an ideal reconstruction of the hypoplastic thumbs of Type III B \& C.

\section{Conflicts of Interest}

None declared.

\section{References}

1 Light TR, Gaffey JL. Reconstruction of the hypoplastic thumb. J Hand Surg Am 2010;35(3):474-479

2 Muller W, Die Angeborenen Fehlbildungen der menschlichen Hand. Leipzig: George Thieme; 1937

3 Blauth W. [The hypoplastic thumb]. Arch Orthop Unfallchir 1967;62(3):225-246

4 Manske PR, McCarroll HR Jr. Reconstruction of the congenitally deficient thumb. Hand Clin 1992;8(1):177-196

5 Buck-Gramcko D. Congenital malformations of the hand and forearm. Chir Main 2002;21(2):70-101
6 Soldado F, Zlotolow DA, Kozin SH. Thumb hypoplasia. J Hand Surg Am 2013;38(7):1435-1444

7 Tay SC, Moran SL, Shin AY. Cooney WP III. The hypoplastic thumb. J Am Acad Orthop Surg 2006;14(6):354-366

8 Mende K, Suurmeijer JA, Tonkin MA. Surgical techniques for reconstruction of the hypoplastic thumb. J Hand Surg Eur Vol 2019;44(1):15-24

9 Chow CS, Ho PC, Tse WL, Hung LK. Reconstruction of hypoplastic thumb using hemi-longitudinal metatarsal transfer. J Hand Surg Eur Vol 2012;37(8):738-744

10 Schneider W, Reichert B, Pallua N, Meyer H. Correction of hypoplastic thumb by free transfer of metatarsal bone: a case report. Microsurgery 1993;14(7):468-471

11 Foucher G, Medina J, Navarro R. Microsurgical reconstruction of the hypoplastic thumb, type IIIB. J Reconstr Microsurg 2001;17(1):9-15

12 Tu YK, Yeh WL, Sananpanich K, et al. Microsurgical second toe-metatarsal bone transfer for reconstructing congenital radial deficiency with hypoplastic thumb. J Reconstr Microsurg 2004;20(3):215-225

13 Manske PR, Rotman MB, Dailey LA. Long-term functional results after pollicization for the congenitally deficient thumb. J Hand Surg Am 1992;17(6):1064-1072

14 Tan JS, Tu YK. Comparative study of outcomes between pollicization and microsurgical second toe-metatarsal bone transfer for congenital radial deficiency with hypoplastic thumb. J Reconstr Microsurg 2013;29(9):587-592

15 Ozols D, Butnere MM. Aigars Petersons methods for congenital thumb hypoplasia reconstruction. A review of the outcomes for ten years of surgical treatment. Medicina (B Aires) 2019;55:610 